\title{
Adult and Nymphs of Microtriatoma trinidadensis (Lent, 1951) (Hemiptera: Reduviidae) Caught from Peridomestic Environment in Bolivia
}

\author{
J De la Riva/ ${ }^{+}$, A Matias, M Torrez, E Martínez, JP Dujardin* \\ Instituto Nacional de Laboratorios en Salud, Rafael Zubieta $\mathrm{N}^{\circ}$ 1889, La Paz, Bolivia *Unité Mixte de \\ Recherche IRD-CNRS 9926, Montpellier, France
}

This is the first report of adult and nymphs (20 nymphs of all stages and 4 adults) of Microtriatoma trinidadensis (Lent 1951) (Hemiptera: Reduviidae: Triatominae) collected in peridomestic environment, in the department of La Paz, Bolivia.

These specimens were associated to Rhodnius stali Lent, Jurberg \& Galvão 1993. The exceptional finding of M. trinidadensis in peridomestic environment, illustrates the general tendency of triatominae to adapt to human dwellings and dependences.

Key words: Microtriatoma trinidadensis - Rhodnius stali - peridomestic - coprophagy - Bolivia

Microtriatoma mansosotoi Prosen \& Martínez 1952 was described by Carcavallo et al. (1976) and synonymized later with $M$. trinidadensis Lent, 1951 by Lent and Wygodzinsky (1979), who described adults and fifth nymph only, inferring from them the characteristics of the remaining stages.

The first specimens of Microtriatoma reported in Bolivia as M. mansosotoi Prosen \& Martínez 1952 were collected in the Chapare (Department of Cochabamba, Bolivia) (Torrico 1958) and in Santa Cruz (Department of Santa Cruz, Bolivia) at the periurban zone (Wygodzinsky 1958). Since then, Microtriatoma was mentioned many times in South America (Venezuela, Colombia, Surinam, Peru, Bolivia and Brazil) (Lent \& Wygodzinsky 1979, Miles et al. 1981, Pinto 1992), whereas it was reported only a few times in Central America (Trinidad and Panama) (Carcavallo et al. 1999).

This species is known to be associated with palms and hollow trees, hidden in tree cavities such as folded leaves, especially within nests of Didelphis marsupialis (Lent \& Wygodzinsky 1979, Miles et al. 1981). According to Miles et al. (1981), $M$. trinidadensis could feed on opossum in the wild. Under laboratory conditions it could feed readily on mice at least during some time, after what it

\footnotetext{
This work has benefited from international collaboration through the ECLAT network.

${ }^{+}$Corresponding author. Fax: +591-2-225280. E-mail: jascemineriv@mixmail.com

Received 17 July 2000

Accepted 22 March 2001
}

died. M. trinidadensis has been found naturally infected by Trypanosoma cruzi (Miles et al. 1981, Silveira 1998).

This work describes for first time the presence of $M$. trinidadensis in peridomestic environment in La Paz Department, Bolivia (Fig. 1) associated with Rhodnius stali Lent, Jurberg and Galvão, 1993 and provides a morphological description of all nymphal instars.

\section{MATERIALS AND METHODS}

Field survey - During May 1998, we carried out a field survey aiming to collect any Triatominae in domestic and peridomestic environment in Alto Beni, a sub-Andean region of the Department of La Paz (Fig. 1) at the border with Amazonian region $\left(15^{\circ} 19^{\prime} \mathrm{S}, 67^{\circ} 32^{\prime} \mathrm{W}\right)$. It has an annual mean temperature of $25.89^{\circ} \mathrm{C}$ and a mean relative humidity of $80.6 \%$.

\section{Insects}

Morphological examination - The external morphological examination and classic taxonomic identification was performed without dissection of genitalia, using as reference the description of Lent and Wygodzinsky (1979). Only specimens identified as M. trinidadensis Lent 1951 were included in the subsequent studies. Eleven nymphs of this species were stored at $-70^{\circ} \mathrm{C}$ for further studies and the remaining 9 were included in the INLASA collection. Two adults were sent later to the reference laboratory of Instituto Oswaldo Cruz (IOC), Rio de Janeiro, Brazil for morphological confirmation and deposited by Carcavallo at the IOC collection.

Parasite search - Rectal contents of 3 adults and 3 fifth instar nymphs were examined microscopically for the presence of flagellates. 


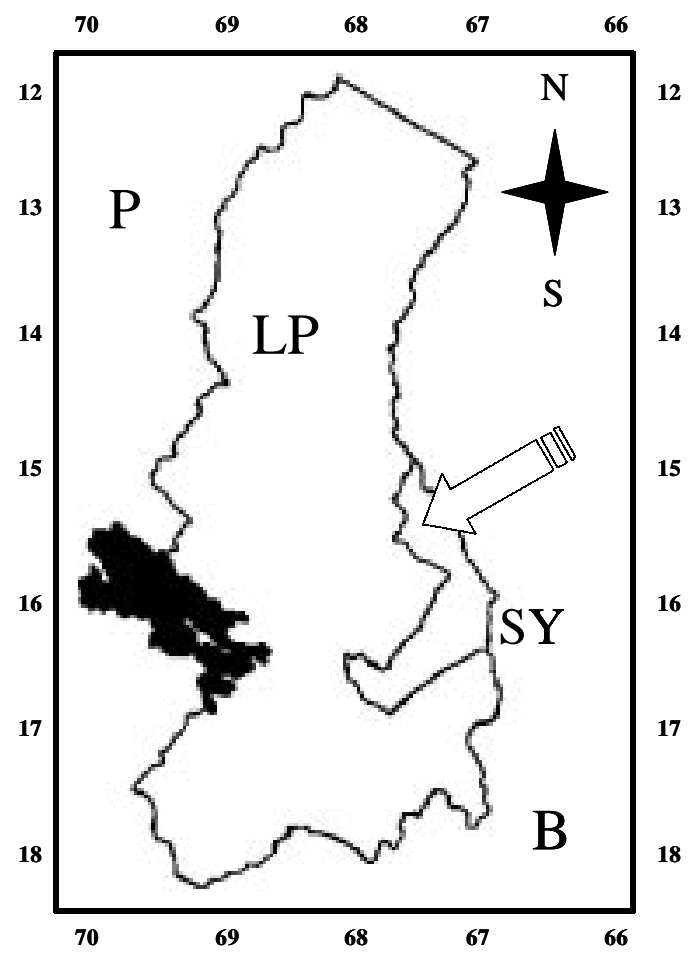

Fig. 1: map of the Departament of La Paz (see LP) in Bolivia (see B) showing the location of study area (Alto Beni, see arrow) in the province of South Yungas (see SY). Numbers external to the box are latitudes and longitudes. The black zone represents the Titikaka Lake. P: Peru; B: Bolivia; N: north; S: south
Morphometrics - Using a monocular micrometer eyepiece (10x), we performed 12 head and 3 wing measurements in 2 adult specimens ( 1 male and 1 female). For comparison of the specimens collected with known material, 2 other adults were measured from the Carcavallo collection at IOC: 1 type female of $M$. trinidadensis (named here F2), and 1 allotype female of $M$. mansosotoi (named here F1).

Head measurements (Fig. 2) - Maximum diameter of eye (DE); length of first rostrum segment (R1); lenght of second rostrum segment (R2); lenght of third rostrum segment (R3); anteclypeus width (AC); outer distance between eyes (OE); inner distance between eyes or synthlipsis (IE); external distance between ocelli (EO); lenght of antenniferous tubercle (AT); anteocular distance (AO); postocular region (PO); head length (HL). The length of antenniferous tubercle is an oblique measure, not parallel to the head length measurement.

Wing measurements were the linear distance between the points indicated in Fig. 3: Wab, distance between A and B; Wac, distance between A and $\mathrm{C}$; and Wad, distance between $\mathrm{A}$ and $\mathrm{D}$.

\section{RESULTS}

Insects - A total of 24 specimens collected were identified as $M$. trinidadensis, 20 nymphs: 2 first instar (N1), 2 second instar (N2), 1 third instar (N3), 3 fourth instar (N4), 12 fifth instar (N5); and 4
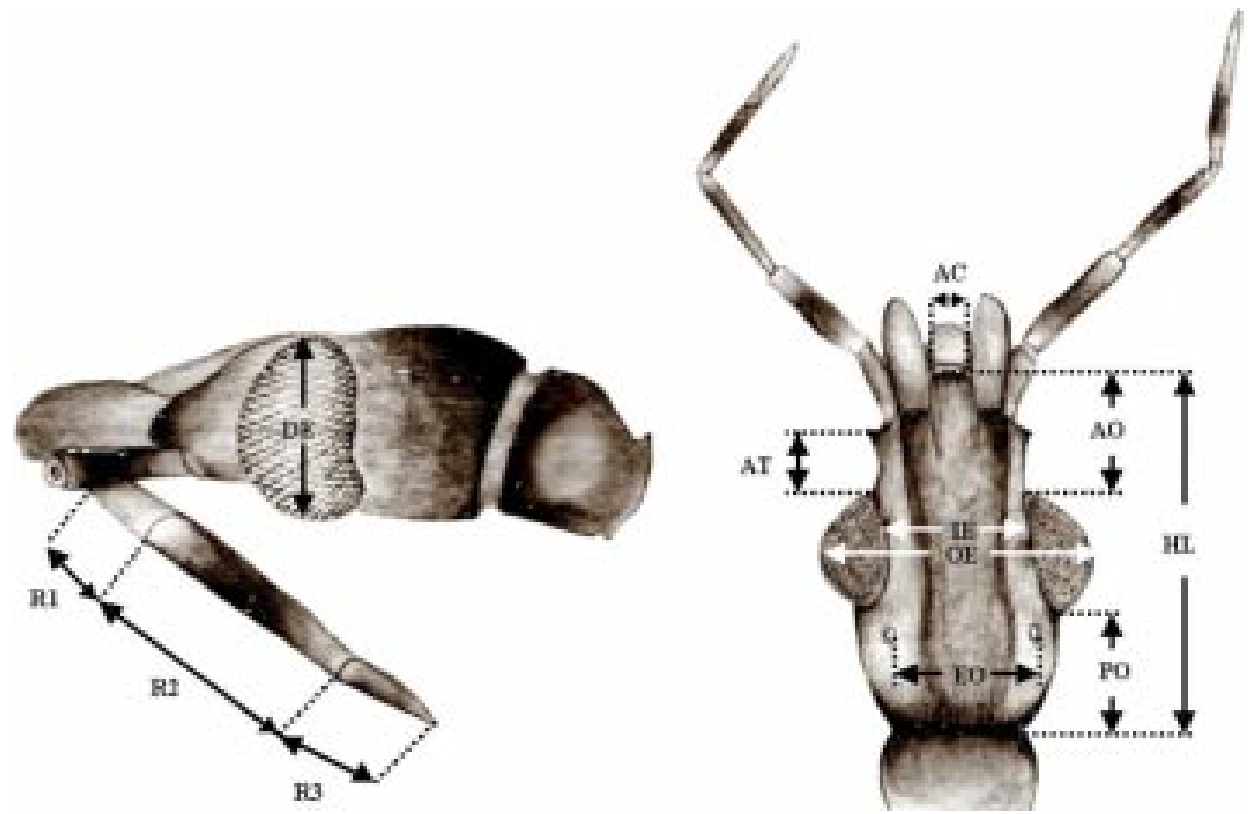

Fig. 2: lateral and dorsal view of the head of an adult of Microtriatoma trinidadensis. DE: maximum diameter of eye; R1: length of first rostrum segment; R2: length of second rostrum segment; R3: length of third rostrum segment; AC: anteclypeus width; OE: outer distance between eyes; IE: inner distance between eyes or synthlipsis; EO: external distance between ocelli; AT: length of antenniferous tubercle; AO: anteocular distance; PO: postocular region; HL: head length. Note genae overtaking the clypeus, a typical character for the tribe Bolboderini 


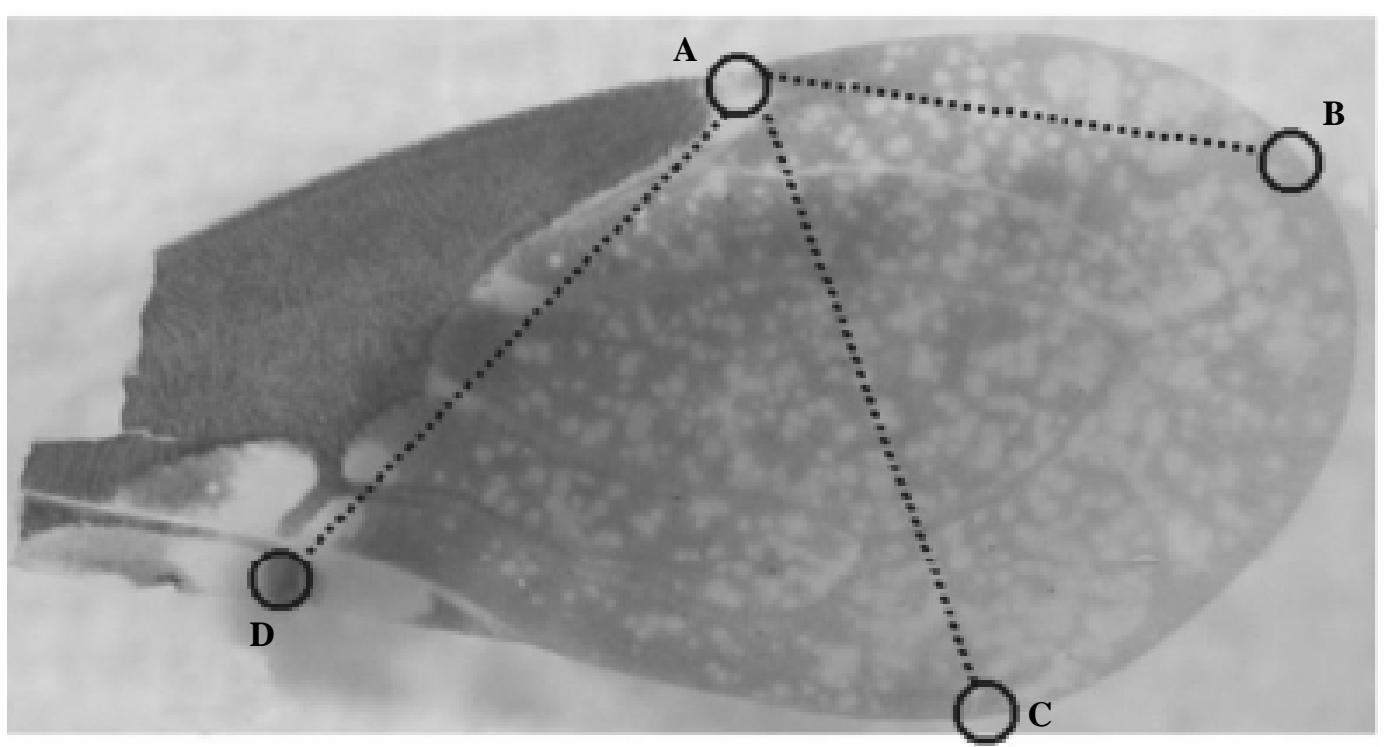

Fig. 3: dorsal view of the right wing of female Microtriatoma trinidadensis. Circles indicate landmarks labeled A, B, C, D, and dashed lines between them indicate the measurements taken. For instance, Wab is the distance between landmarks A and B, Wac the distance between A and C, and Wad the distance between A and D. Note the pale spots on hemelytra, typical of M. trinidadensis

adults ( 2 females and 2 males). All the 24 specimens came from one house only, out of the 101 houses examined. The specimens collected were found in a chicken coop built with material from the palm tree Attalea phalerata. It is worth mentioning that chicken coops were not frequent in this area (there were 20 of them for 101 houses), and that the other chicken coops were generally made of different materials (adobe for instance). Another particularity was the joint finding, at the same place, of a few Rhodnius stali together with $M$. trinidadensis (Matias et al. 2001).

In the laboratory, various potential hosts (chicken, human, mice) were proposed to allow the insects to feed, without success. The unique feeding behavior observed was a fifth instar nymph probing feces of $R$. stali, which apparently could trigger its last molting.

Parasite search - No flagellate was observed in the fecal drops.

Morphological and morphometric description - As hypothesized by Lent and Wygodzinsky (1979), all nymphs presented spongy fossulae on the 3 pairs of legs. In both adults and nymphs, femur and tibia were without spines or denticles on under surface, and proximal and distal extremities of each segment of the legs were generally darker. Thorax was not granulose, with numerous short scale-like setae. The connexivum patterns on the first (N1) and second instar nymph (N2) were poorly noticeable, and became more conspicuous on the following stages (N3, etc.). The overall color of $\mathrm{N} 1$ and $\mathrm{N} 2$ was tenuous rose and maintained so during their lifetime (two weeks). This color of nymphs abruptly changed from tenuous rose in the first instars $(\mathrm{N} 1, \mathrm{~N} 2)$ to obscure brown in the next ones (N3, N4, N5 and adults).

Another feature changing between N2 and N3 was the relative lengths of head and rostrum. In the first nymphs $(\mathrm{N} 1, \mathrm{~N} 2)$, the rostrum reached the neck. From the third instar nymph to the following stages, the size of second rostrum segment (R2) grew up so that the complete rostrum presented larger dimensions than the length of the head. Our measurements (Table) were compatible with the dimensions of two other specimens of Microtriatoma conserved as type and allotype in the Carcavallo collection at IOC: one female of $M$. mansosotoi (F1, Table), and one female of $M$. trinidadensis (F2, Table).

\section{DISCUSSION}

This is the first report of M. trinidadensis in the peridomestic environment. The main morphological characteristics of our sample were as described by Lent and Wygodzinsky (1979). We could confirm the presence of spongy fossulae on the 3 legs of all instars, and observe some abrupt morphological changes between second and third instar nymphs: the color, the visibility of connexivum spot (Fig. $4 \mathrm{~b}$ ) and relative proportions of head and rostrum.

Interestingly, our measurements reproduced almost exactly the dimensions of $M$. mansosotoi 
female allotype, as identified in Cochabamba (Villa General Román, Chapare, Bolivia) by Torrico (1958). This could suggest that the Bolivian population of M. trinidadensis could represent a slight but stable geographic variation from the $M$. trinidadensis holotype.

The present finding adds a third Department of Bolivia (La Paz) to the Bolivian distribution of $M$. trinidadensis. The presence of $M$. trinidadensis just in one dwelling, out of 101 checked, could appear as an accident. However, not the 101 dwellings had chicken coops: 20 chicken coops were examined, of which 5 were positive for the presence of $R$. stali Lent, Jurberg and Galvão, 1993 (Dujardin et al. 2000), and M. trinidadensis was found in 1 of these 5 chicken coops. The presence of nymphs of all instars suggests that $M$. trinidadensis was breeding there. The apparent absence of eggs was probably due to their very small size $(0.8 \mathrm{~mm}$ of half diameter and half length

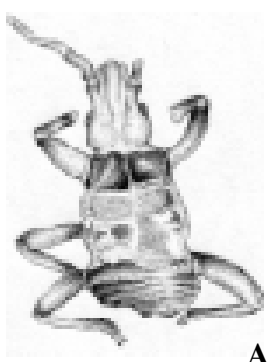

$\mathbf{A}$
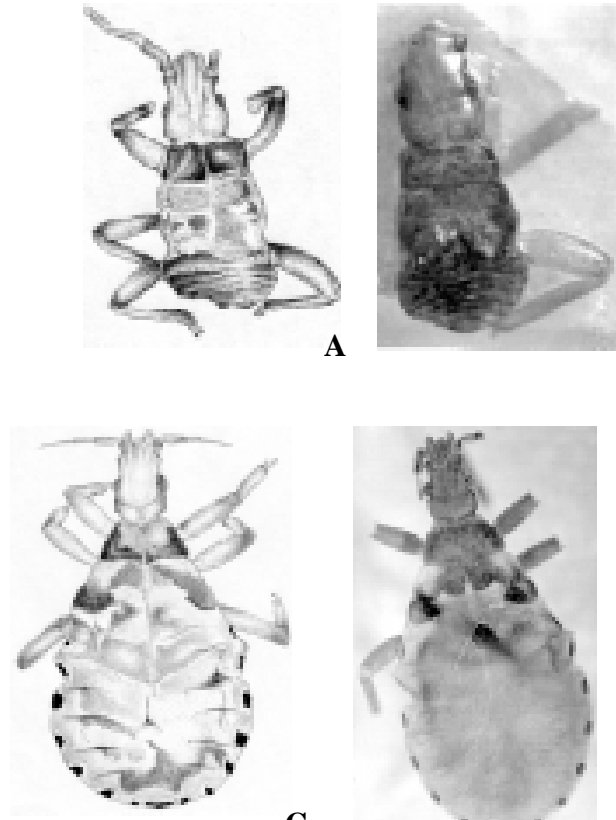

C
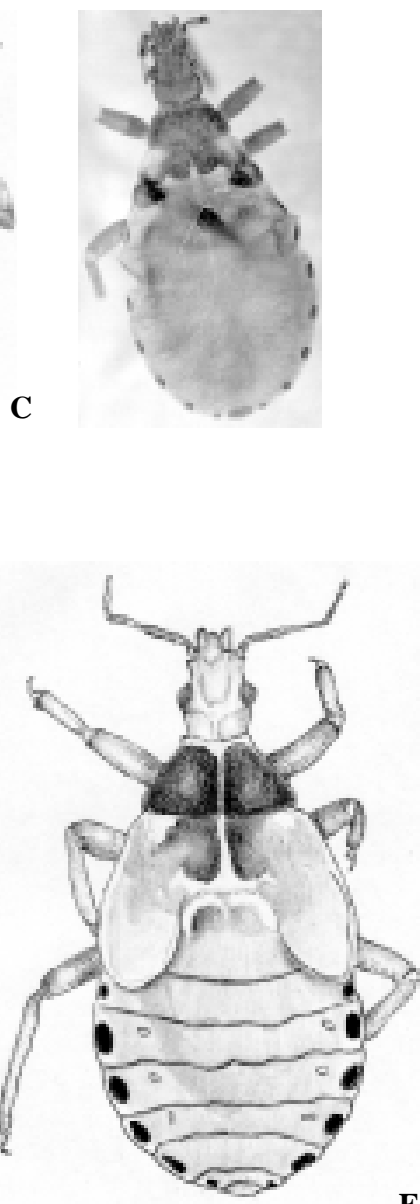

E
B
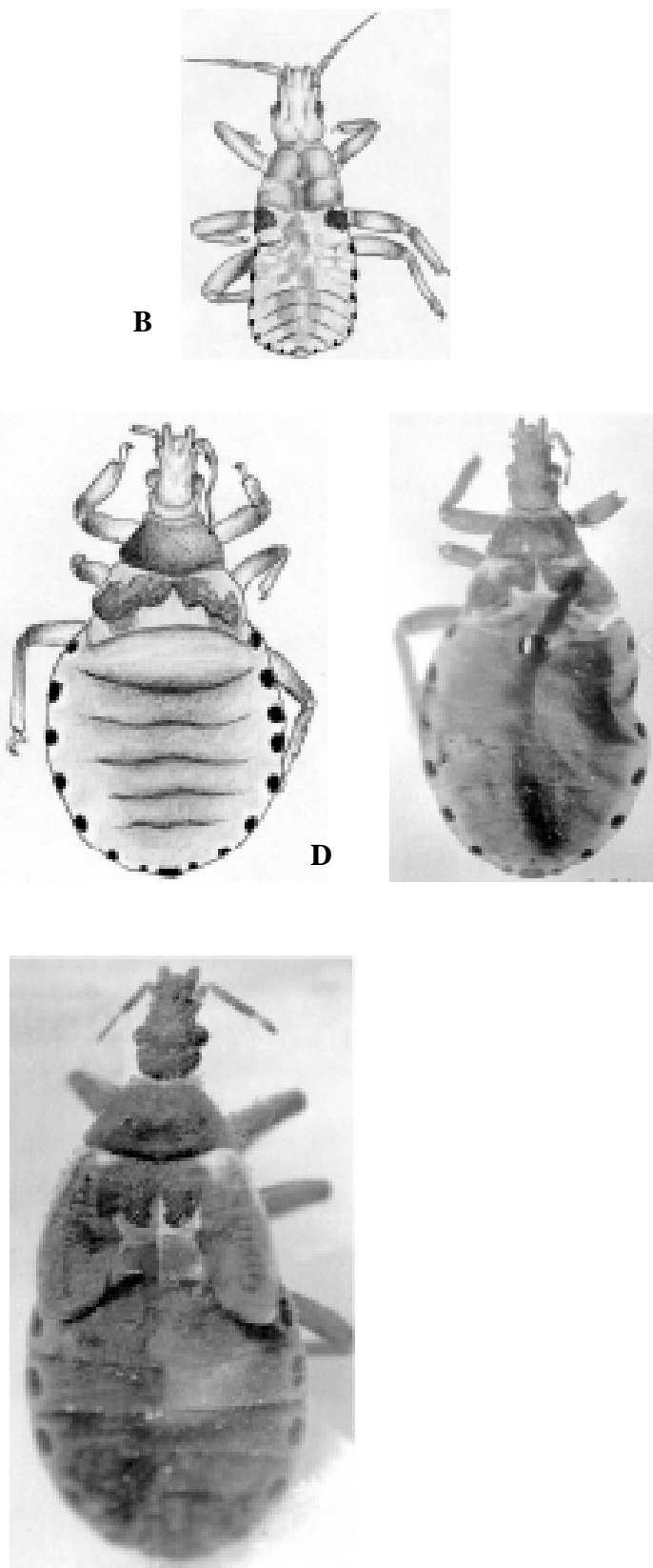

Fig. 4: nymphs drawings and corresponding photographs - A: first instar; B: second instar, drawing only; C: third instar; D: fourth instar nymph; E: fifth instar nymph 
TABLE

Metric properties (mm) of Microtriatoma trinidadensis

\begin{tabular}{llcccc}
\hline Trait & Code & F & M & F1 & F2 \\
\hline Left wing & Wab & 2.90 & 2.90 & nd & nd \\
& Wac & 3.00 & 3.00 & nd & nd \\
& Wad & 2.95 & 2.90 & nd & nd \\
Right wing & Wab & 3.00 & 2.90 & nd & nd \\
& Wac & 3.10 & 3.00 & nd & nd \\
& Wad & 2.90 & 2.85 & nd & nd \\
Head & DE & 0.48 & 0.50 & 0.50 & 0.44 \\
& R1 & 0.24 & 0.26 & 0.30 & 0.40 \\
& R2 & 0.70 & 0.72 & 0.60 & 0.84 \\
& R3 & 0.30 & 0.30 & absent & absent \\
& AC & 0.14 & 0.16 & 0.14 & 0.14 \\
& OE & 0.90 & 0.92 & 0.96 & 0.84 \\
& IE & 0.52 & 0.50 & 0.46 & 0.40 \\
& EO & 0.58 & 0.60 & 0.58 & 0.50 \\
& AT & 0.22 & 0.22 & 0.24 & 0.28 \\
& AO & 0.50 & 0.50 & 0.52 & 0.56 \\
& PO & 0.40 & 0.42 & 0.44 & 0.50 \\
& HL & 1.32 & 1.34 & 1.34 & 1.36 \\
\hline
\end{tabular}

Body size (N5)6.5 (N4)5.6 (N3)4.2 (N2)2.6 (N1)1.5

F: female adult from La Paz (Bolivia); M: male adult from La Paz (Bolivia); F1: allotype, female, of $M$. mansosotoi (from Cochabamba, Bolivia, Torrico 1958); F2: holotype, female, of M. trinidadensis (from Arina, Trinidad); nd: not dissected; body size: without genae; Wab: distance between A and B; Wac: between A and C; Wad: between A and D (see Fig. 3); DE: maximum diameter of eye; R1: length of first rostrum segment; R2: length of second rostrum segment; R3: length of third rostrum segment; AC: anteclypeus width; OE: outer distance between eyes; IE: inner distance between eyes; EO: external distance between ocelli; AT: length of antenniferous tubercle; AO: anteocular distance; PO: postocular region; HL: head length (see Fig. 2).

$1.1 \mathrm{~mm}$ as described by Barata (1995), making them almost invisible.

Our search for flagellates was negative. This does not discard the possibility of infection by $T$. cruzi. For the specimens collected in this survey, the probable source of food was hens, which, like birds in general, are known to be refractory to the T. cruzi infection. In other associations (as with opossum), M. trinidadensis has been found infected by $T$. cruzi (Miles et al. 1981, Silveira 1998).

These specimens were collected in a chicken coop which was also colonized by $R$. stali, a similar association has been reported before with $R$. robustus Larrouse 1927 in Venezuela (Lent \& Wygodzinsky 1979). These references and our observation of a $M$. trinidadensis nymph probing feces of $R$. stali could represent some kind of preda- tory behavior and could reflect a true biological association. It also could provide a first explanation to the presence of $M$. trinidadensis in peridomestic structures. In support of this, Belminus peruvianus Herrer, Lent and Wygodzinsky, 1954 (another Bolboderini), was found to colonize houses in the Marañon Valley of Peru, where it was observed to attack the Chagas disease vector Panstrongylus herreri Wygodzinsky 1948 (Herrer 1955). Similarly, cleptohematophagy of B. herreri Lent \& Wygodzinsky, 1979 on specimens of $R$. prolixus Stål 1859 has been described in Colombia (Sandoval et al. 2000). Whatever the mechanism explaining this unusual ecotope for $M$. trinidadensis, our finding illustrates again the general tendency of Triatominae to adapt to domestic structures (Dujardin et al. 2000).

As long as the hypothesis is true of a biological association between $R$. stali and M. trinidadensis, in a geographic area where $R$. stali is known to adapt to domestic structures (Dujardin et al. 2000, Matias et al. 2001), M. trinidadensis could be just following its source of food.

\section{REFERENCES}

Barata JMS 1996. Aspectos morfológicos de ovos de Triatominae. In CJ Schofield, JP Dujardin, J Jurberg (eds) Proceedings of the International Workshop on Population Genetics and Control of Triatominae, Santo Domingo de los Colorados, Ecuador, 1995. Instituto Nacional de Diagnostico y Referencia Epidemiologicos, Mexico DF, p. 55-58.

Barata JMS 1998. Macroscopic and exochorial structures of triatominae eggs (Hemiptera, Reduviidae), In RU Carcavallo, I Galindez Girón, J Jurberg, H Lent (eds), Atlas of Chagas Disease Vectors in the Americas, Vol II, Fiocruz, Rio de Janeiro, p. 409434.

Carcavallo R, Barreto P, Martinez A, Tonn R 1976. El género Microtriatoma Prosen \& Martínez, 1952 (Hemiptera, Reduviidae). Bol Dir Malariol Saneam Amb XVI: 231-240.

Carcavallo RU, Curto de Casas SI, Sherlock IA, Galindez Giron I, Jurberg J, Galvão C, Mena Segura C, Noireau F 1999. Geographical distribution and altilatitudinal dispersion. In RU Carcavallo, I Galindez Girón, J Jurberg, H Lent (eds), Atlas dos Vetores da Doença de Chagas nas Américas, Vol III, Fiocruz, Rio de Janeiro, p. 747-792.

Herrer A 1955. Tripanosomiasis americana en el Perú. I. El insecto vector y los animales que actúan como reservorios de la enfermedad de Chagas en la región suroccidental. Rev Med Exp Lima 9: 23-37.

Dujardin JP, Schofield CJ, Panzera F 2000. Les Vecteurs de la Maladie de Chagas. Recherches Taxonomiques, Biologiques et Génétiques, Académie Royale des Sciences d'Outre-Mer, Classe des Sciences Naturelles et Médicales, Belgique, $162 \mathrm{pp}$.

Lent H, Wygodzinsky P 1979. Revision of the Triatominae (Hemiptera, Reduviidae) and their sig- 
nificance as vectors of Chagas disease. Bull Amer Mus Nat Hist 163: 123-163.

Matias A, de la Riva J, Martinez E, Torrez M, Dujardin JP 2001. Domiciliation process of Rhodnius stali (Hemiptera, Reduviidae) in the Alto Beni (La Paz Bolivia). Submitted to Trop Med Internl Health.

Miles A, de Souza A, Póvoa M 1981. Chagas disease in the Amazon basin III. Ecotopes of ten triatomine bug species (Hemiptera: Reduviidae) from the vicinity of Belém, Para State, Brazil. J Med Entomol 18: 266-278.

Pinto J 1992. Epidemiology of Chagas disease. In S Wendel, Z Brener, M Camargo, A Rassi (eds), Chagas' Disease (American Trypanosomiasis) : its Impact on Transfusion and Clinical Medicine, Soc
Bras de Hematol e Hemoterapia, ISBT Brazil 92, p. 49-79.

Sandoval CM, Joya MI, Gutierrez R, Angulo VM 2000. Cleptohaematophagy of the triatomine bug Belminus herreri. Med Vet Entomol 14: 100-101.

Silveira AC 1998. Vigilância epidemiológica da doença de Chagas na Amazônia. In CJ Schofield, C Ponce (eds), Proceedings Second International Workshop on Population Genetics and Control of Triatominae, Tegucigalpa, p. 32-35.

Torrico RA 1958. Casuística de la enfermedad de Chagas en Bolivia. An Laboratorio Central 4: 3-13.

Wygodzynsky P 1958. Notas y descripciones de reduviidae bolivianas. Acta Zool Lilloana XVII: 293-320. 